\title{
Transmedia Design Framework. Design-Oriented Approach to Transmedia Research
}

\author{
Mariana Ciancia
}

Politecnico di Milano, Italy

doi: 10.7358/ijtl-2015-001-cian

mariana.ciancia@polimi.it

\begin{abstract}
The contemporary mediascape is witnessing the emergence of crossmedia and transmedia structures: phenomena that foster the sharing of meaning-making processes between producers and audiences, shaping society and influencing media habits. There are also a whole industry and a newborn scientific community that want to go beyond the conceptual confusion that covers these terms, trying to find definitions and sharing practices to develop compelling stories. This paper defines the "design-oriented" approach used for my $\mathrm{PhD}$ research into the transmedia field. The description of methodology and methods becomes an opportunity to develop observations about the role of the researcher in studying this field, and the relationship between researching and teaching experience.
\end{abstract}

Keywords: transmedia practice; transmedia research; transmedia design; multi-channel communication; design culture; design practice; methodology.

\section{INTRODUCTION}

We live in a society rich with a growing number of messages spread by multichannel and multi-modal devices (Kress and Leeuwen 2001; Manovich 2002; Piredda 2008). What is emerging from a phenomenological approach to contemporary mediascape is the rising importance of multi-channel structures that completely change the role of the audience, allowing the development of widespread creativity through the collaborative creation and the collective consumption of narrative worlds. Focusing on the domains of media studies (Lévy 1996; Jenkins 2006; Jenkins, Ford, and Green 2013) and design research 
(Brown 2008; Ehn 2008; Moggridge 2010), the core topic of my research is those multi-channeled structures able to foster the sharing of meaning-making processes between producers and audiences, shaping society and influencing media habits: the transmedia phenomena.

The emerging issues from the literature review were a non-common definition of "what transmedia is" and a lack of sharing practices in transmedia project development. In fact, this research aims to identify the main features of transmedia projects to build a glossary that can be shared, and to contribute to the development of a useful tool for transmedia practice (Dena 2009). An instrument that I term "transmedia design framework" is intended to become a conceptual and operational tool for designing engaging narrative environments, not only for big Hollywood productions, but also for everyday scenarios. In doing this, I aim to derive tools and processes from design practices because, according to Friedman (1999):

Design research is unusual for several reasons. First among them is that design is both an intellectual discipline and an applied discipline. Design research operates on several levels, both theoretical and applied. The questions of design research methods therefore span a number of issues. The second important aspect of design is that it is an integrative discipline, frequently required to operate across disciplines and engage multiple research methods. Finally, the variety of fields involved in design is far larger than we find in most disciplines. (Friedman 1999, in Pizzocaro 2010, 92)

The aim of this paper is to highlight some reflections about methodologies and methods in the transmedia research field. Therefore, the first part of the work briefly describes the topic, the objectives and the expected results of the $\mathrm{PhD}$ research. After this, the paper focuses on research phases, methodology, and methods to show some considerations of the role of the researcher in studying the transmedia field.

\section{TRANSMEDIA DESIGN FRAMEWORK: \\ RESEARCHING THE TRANSMEDIA FIELD}

Due to the rising number of multi-modal devices and the higher number of messages conveyed across several channels, the designer has a key role as mediator to bring the different social contexts together in a mutual understanding. Starting from these assumptions, and according to projects and thoughts developed over the years, the aim of my research is the understanding of a form of communication able to merge different languages, media, and technologies, and to rethink participatory processes. 
I identified transmedia practice as a possible procedure to address the issue of contemporary complexity through a phenomenological approach to the coeval reality. This allowed me to concentrate on a real cultural paradigm that allows people to become aware of the prominent role played in the contemporary mediascape, focusing on the storyteller's ability to support multiple points-of-view. This is because "[a]s meaning-makers today, we, especially the youngest of us, increasingly live our lives across institutions and media, and we make meanings with all their resources that no single medium or institution can control”. (Lemke 2011, 579)

Issues emerging from the literature review include conceptual confusion (Renira, Rampazzo, and Gambarato 2013) regarding the term "transmedia" and other interchangeably used words, and a lack of sharing practices in transmedia project development. In fact, what we are witnessing right now "is a whole industry which is trying to find coherent best practices to address the challenges and opportunities that this situation brings" (Staffans 2012, 14). This is an area of interest that intersects different research fields: "[e]veryone is looking at transmedia from their own angle. This is very natural and exactly as it should be, as everyone have [sic] their own area of expertise" (Staffans 2012, 26). Having a design education, I applied a designer's way of thinking (Cross 2001) with the purpose of generating:

[t]he frameworks of meaning where the continuous conversation between other actors of the system can innovate taking on new meanings. In other words, when the product is knowledge, the design research becomes one of the main drivers of innovation, and the centres in which it takes place assume the role of real "design Knowledge lab”. (Manzini 2000, 15)

In response to the lack of common practices in the design of transmedia projects, the output will be a conceptual and operational tool for designing compelling narrative environments: what I call the transmedia design framework. That is, a kind of research of "semifinished research products" (Manzini $2000,15)$, a type of knowledge that can be stored and employed in the future.

\section{Design-Oriented ApPROACH to TRANSMEDIA RESEARCH}

In 2012, transmedia was described by Simon Staffans as "[t]he oldest of the old that at the same time is the newest of the new" (20). It is possible to acknowledge that the practice of telling stories across multiple channels has a long tradition (for example, the Bible is indicated as the first great transmedia project), at the same time highlighting its ongoing importance. It is a practice 
made up of tacit knowledge, which people work with in an intuitive manner. This research is an attempt to identify the common elements in the different points-of-view in order to build a glossary that can be shared, contributing to the development of a useful tool for transmedia practice. The approach that led me to organize the research path in three phases was the model developed by Chow and Jonas (2008): analysis, synthesis and projection.

\subsection{Generative Communication}

The first phase of the design-oriented approach was devoted to the exploration of the multi-channel communication field and the definition of its theoretical foundations (Analysis-Inductive Phase, from Chow and Jonas 2008). It started from the assumption that the analysis phase is a key step for any design process, allowing for the discovery of data and concepts able to foster research development.

The aim of this phase was to understand different communication scenarios through a literature review and desktop research in the fields of media studies. What emerged from a phenomenological approach to contemporary mediascape was the rising importance of multi-channel structures that completely change people's media habits, leading the research to focus on transmedia practice. This was investigated through the analysis of state of the art and by attending conferences. Only in recent years has the field seen the development of scientific research on the topic, thus it was necessary to attend these meetings in order to grasp the ongoing changes.

There were three outputs of the first phase: two conceptual and one operational. The first was the investigation of multi-channel paradigms and the consequent building of a positioning matrix, according to the taxonomy highlighted by Christy Dena (2009). This output led me to discriminate between crossmedia and transmedia systems according to the story field. Therefore, it is possible to recognize structures in which the story is adapted in different channels (crossmedia), or if it is spread through them (intracompositional transmedia phenomena and intercompositional transmedia phenomena). The second was the identification of transmedia practice as a possible approach to overcome contemporary complexity, a scenario characterized by changes in audience behaviors, development in the technological field and the evolution of the participation processes. The last output was the definition of an analytical tool to deal with the second phase - an analysis form (see Tab. 1) - with the aim of understanding and highlighting the main features of transmedia projects. The form opens by listing a series of general information, and is structured in three sections that deal respectively with the narrative, the structure, and the production phase. 
Table 1 - Detailed description of listed items in the analysis form.

\begin{tabular}{|c|c|c|}
\hline \multicolumn{3}{|c|}{ ANALYSIS FORM } \\
\hline TOPIC & SuBJECT & DESCRIPTION \\
\hline \multirow[t]{4}{*}{ GENERAL INFORMATION } & Title & \multirow{4}{*}{$\begin{array}{l}\text { General information } \\
\text { about project and } \\
\text { obtained results. }\end{array}$} \\
\hline & $\begin{array}{l}\text { General } \\
\text { Description }\end{array}$ & \\
\hline & Statistics & \\
\hline & Awards & \\
\hline \multirow[t]{3}{*}{ SECTION A I STORYTELLING } & 1. Synopsis & $\begin{array}{l}\text { Brief summary of the } \\
\text { story. }\end{array}$ \\
\hline & 2. Story Elements & $\begin{array}{l}\text { Identification of charac- } \\
\text { ters, context and spatial } \\
\text { configuration of the } \\
\text { story world and core } \\
\text { themes. }\end{array}$ \\
\hline & 3. Action Flow & $\begin{array}{l}\text { How the action is } \\
\text { conveyed. }\end{array}$ \\
\hline \multirow[t]{3}{*}{ SECTION B I STRUCTURE } & 4. Structure & $\begin{array}{l}\text { Identification of the } \\
\text { type of structure } \\
\text { according to Dena's } \\
\text { (2009) taxonomy: } \\
\text { crossmedia, intracom- } \\
\text { positional transmedia } \\
\text { phenomenon or inter- } \\
\text { compositional trans- } \\
\text { media phenomenon. }\end{array}$ \\
\hline & $\begin{array}{l}\text { 5. Platform and } \\
\text { Channels }\end{array}$ & $\begin{array}{l}\text { List of platforms and } \\
\text { channels involved in the } \\
\text { project. }\end{array}$ \\
\hline & 6. Engagement & $\begin{array}{l}\text { How the audience } \\
\text { interaction is designed. }\end{array}$ \\
\hline \multirow[t]{3}{*}{$\begin{array}{l}\text { SECTION C I } \\
\text { BUSINESS AND PRODUCTION }\end{array}$} & 7. Team & $\begin{array}{l}\text { Identification of roles, } \\
\text { responsibilities, and } \\
\text { skills. }\end{array}$ \\
\hline & 8. Business Model & $\begin{array}{l}\text { Description of project } \\
\text { workflow, business, and } \\
\text { distribution model. }\end{array}$ \\
\hline & 9. $\mathrm{R} \& \mathrm{D}$ & $\begin{array}{l}\text { Innovative elements of } \\
\text { the analyzed project. }\end{array}$ \\
\hline
\end{tabular}


The first section, storytelling, requires a brief summary of the story (synopsis) and a description of the narrative elements. These include the specification of primary and secondary characters and the highlighting of the relationships between them, the description of the narrative world, and the identification of the main themes. The last item concerns the analysis of the actions (agency). Andrea Phillips $(2012,93)$ declared that "[i]f there is no action, then nothing is happening; if nothing happens, you don't have a story. So one of the primary tasks of a storyteller is to effectively and compellingly convey action", supporting the importance of action. Using her works and reflections, I have included the agency item with the aim of collecting useful information for the structure section. The aim is also to determine if the action is kept in one medium or if it is conveyed over multiple media (Phillips 2012, 93-97).

This entry marks the connection with Section B, Structure, in the analysis of the transmedia project. The first item is the identification of the phenomenon according to Dena's (2009) classification. The second item is the description of platforms and channels involved in the structure. As mentioned, the role played by the audience is essential within these projects. Therefore, the last item relates to the mechanics of interaction. Specifically, it is related to the recognition of tools of interaction applied by the design team, which can be summarized in three categories: story archaeology, communication, and changing in the story world (Phillips 2012, 119-122). It also provides an analysis of types of challenges proposed, the description of the mechanics of interaction, and the highlighting of the prizes and rewards provided. I have taken the classification proposed by Phillips (2012) for the many types of challenges: puzzle-solving, contribution of content, real-world actions, social engineering challenges, story archaeology, recruitment, social media messaging, and formal games. According to Gambarato (2013) and Hayes (2011), it is useful to match this entire section with maps or diagrams to show the narrative structure, the scheduling, and the audience engagement system.

The last section, business and production, concerns the analysis of the business model and the production pipeline used for the project's development. The first entry (teams) relates to the recognition of all involved figures, including the identification of roles and responsibilities. The second one requires the description of the production pipeline and the identification of the business model: that is, the existence of the "old model" (Pratten, 2011) and new production models that include the potential to enhance the role of the crowd. The last item (research and development, R\&D) describes innovative aspects of the analyzed project. 


\subsection{Tracking Transmedia}

The second phase (Projection-Abductive Phase, from Chow and Jonas 2008) attempts to establish a deep analysis of the transmedia field in order to go beyond the buzzwords through the literature review, desktop research and the case-study method.

The term transmedia was used for the first time in reference to the franchise entertainment super-system that works "to position consumers as powerful players while disavowing commercial manipulation" (Kinder 1991, 119-120). Jenkins went further, coining the term "transmedia storytelling" (2003), and later defined it as "Stories that unfold across multiple media platforms, with each medium making distinctive contributions to our understanding of the world, a more integrated approach to franchise development than models based on urtexts and ancillary products" (2006, 293). There are many attempts to define what transmedia really means. The frequent consequence has been a conceptual confusion of the term and misleading usage of it.

Output of this phase was the description of several case studies and the subsequent identification of the key features of transmedia projects: transmedia storytelling, distribution of content in different media, and audience engagement. I selected two types of case studies: the ongoing projects, and works that are recognized as best practices by the scientific community. In the first case, the choice was driven by the necessity to have a personal involvement with projects, thus create an empathic relationship with the object of study and its community. For this, I needed to move the point-of-view from the objectivity of the researcher, to the subjectivity of an involved user. In both cases, I decided to collect data and information by way of an online research community, a procedure applied by brands to gather qualitative information from discussion forums and social media. More and more often:

[n] ewcomers turn to the communities for social reciprocity and a sense of genuine participation, and they find far more interpretive assistance than comes from the producers. They do so just as the franchises are growing beyond the bounds of individual interpretive capacity, while still retaining, and perhaps even strengthening their appeal. (Lemke 2011, 590)

Therefore, the community becomes essential not only for information and data gathering, but also for contributions to the understanding of narrative worlds. The consequence is that "[i]ncreasingly scholars are joining these communities to learn from them, as well as to use their productions as data". (Lemke 2011,589)

In this work, I describe three of the approximately thirty multi-channel projects (crossmedia and transmedia) analyzed during my research. The first, "Cathy's Book: If Found Call (650) 266-8233", is a transmedia novel experi- 
ment developed by Sean Stewart and Jordan Weisman. Published in 2006 by Running Press, it was printed in Italy the next year by Mondadori. The book looks like the diary of Cathy, the seventeen-year-old main character of the story, who entrusts to her diary the story of the investigation to find her boyfriend, Victor, who suddenly left her. The audience can follow her adventures through the reading of the diary and an envelope full of clues, telephone numbers, pictures, and notes written by Cathy, allowing them to participate in the solving of the mystery. The rabbit hole of the transmedia experience is the telephone number printed on the book cover: by calling this number, it is possible to access a recorded message that will let the adventure begin. This is an experiment that allowed the authors to test " $[\mathrm{h}]$ ow far you could take the publishing model" (Lee 2010). The challenge was taken up by the Red Right Hand Publishing, a Toronto start-up that wanted to test a transmedia book publishing model with the horror project "The Black Chronicle".

The second is "Iron Sky", a comic/science-fiction film directed by Timo Vuorensola (2012), which is characterized by the use of an alternative production pipeline that fosters audience engagement through crowdfunding and crowdsourcing processes. Vuorensola and his team created an alternate reality in which Nazi Germans, taking refuge on the moon in 1945 after the Second World War, later return to conquer the planet Earth. This project was developed with the involvement of the community, which also backed the crowdfunding campaign for the sequel "Iron Sky-The Coming Race" (in development), raising 182,557 USD between May 152013 and July 10 2013. For "Iron Sky", the crowdfunding campaign had the objective to raise money to conclude the movie, whereas for the sequel it was launched for crowdfunding during the pre-production phase to support its development. I am now waiting to receive the first draft of the movie's script: one of the perks included in the "Support Trooper Kit" that I bought.

"The Cosmonaut" is a Spanish science-fiction film produced by Riot Cinema Collective in 2012, which tells the story of Stas and Andrei's arrival at Star City in 1967, where the Soviet Union was training the first cosmonaut. The main feature is the rethinking of the industrial mindset thanks to the application of a new model of production and distribution. Production was characterized by the crowdfunding practice and the release of the film under creative commons licenses. I discovered the project at the "Remix Cinema" workshop (March 24-25 2011, University of Oxford), and I was able to follow the production process thanks to the updates received by the team for my participation in the crowdfunding campaign. I also went to the premiere in Italy organized by the cultural association Kinodromo in Bologna, according to the do-it-yourself (DIY) distribution model. 


\subsection{Tool for Transmedia Design}

The third phase (Synthesis-Deductive Phase, from Chow and Jonas 2008), which is currently in progress, aims to contribute to the spreading of shared practices for the design of narrative environments. The output will be the development of a conceptual and operational tool for transmedia practice, the transmedia design framework. I identified classes that were woven together with the six elements of Aristotle's poetics, translated for the human-computer activity by Brenda Laurel (1991): action, character, thought, language, melody (pattern), and spectacle (enactment). This allowed me to identify three sub-classes, within which I am working to define the sets of procedures and tools that will complete the framework, and that reflect the main features highlighted during the first and the second phase: narrative context, media structure and business model.

In order to develop, test, and verify the framework's elements, I am intertwining my research work with the teaching experience at Politecnico di Milano within the course "Fuoricampo: Identities, new media and storytelling for social innovation". The aim of the course is the design of a transmedia strategy for a social TV (a television based on digital channels and social media) for a peripheral urban area in Milan (Bovisa and Dergano districts). During the analysis phase, the students activated a listening process of the urban area and conducted desktop research of transmedia case studies, which were analyzed according to a form (a synthesis of the analysis form that is described in section 3.1.). The product of this work was a copy strategy of the channel created (Plug Social TV) and the development of a document that describes a multiplatform web series for it. A document was developed to guide the students in the transmedia system's description (see Table 2). It was composed of entries that were identified by analyzing several documents, including the "Transmedia Project Reference Guide (Bible)" (Pratten 2011) and "How to write a Transmedia Production Bible" (Hayes 2011). The document assigned to students was intended to make them understand how the single web format they designed was part of a whole narrative world. That is, systems in which every single channel enhances the audience experience through its specific features provide a synergy between online and offline reality.

Students experimented with the provided tools to develop their own transmedia projects. In particular, the first part (narrative context, media structure and business model) had the objective of guiding the students in the development of the transmedia system, fostering them to think about the creation of a whole narrative world able to enhance the local individual cultures through storytelling. This has led to the design of nine web series whose promos are visible on the YouTube channel Plug Social TV: "Tu Vivi Qui", "Sordi\&Baccani Investigation", "Civico X" (Figure 1), "La Bovisa di Giada", "Das De Man", "Caffè o Tè?", "La Traccia Nascosta", "Hiker", and "Percorsi Incrociati” (Figure 2). 
Table 2 - Detailed description of listed items in the document assigned to students.

\begin{tabular}{|c|c|c|}
\hline \multicolumn{3}{|c|}{ FORM FOR THE TRANSMEDIA DESIGN } \\
\hline TOPIC & SUBJECT & DESCRIPTION \\
\hline \multirow{5}{*}{$\begin{array}{l}\text { NARRATIVE } \\
\text { CONTEXT }\end{array}$} & Tagline & A single-line description of the experience. \\
\hline & Context & Description of the story world's environment. \\
\hline & Synopsis & Brief summary of the story. \\
\hline & $\begin{array}{l}\text { Narrative lines } \\
\text { and plot Points }\end{array}$ & $\begin{array}{l}\text { Definition of narrative lines and identifica- } \\
\text { tion of plot points. }\end{array}$ \\
\hline & Characters & $\begin{array}{l}\text { Description of primary and secondary char- } \\
\text { acters, their backstories and the relation- } \\
\text { ships between them. }\end{array}$ \\
\hline \multirow[t]{7}{*}{$\begin{array}{l}\text { MEDIA } \\
\text { STRUCTURE }\end{array}$} & $\begin{array}{l}\text { Multi-channels } \\
\text { structure }\end{array}$ & $\begin{array}{l}\text { Detailed list of the elements that build } \\
\text { up the project (for example webisode, } \\
\text { mobisode, community hub, game, social TV, } \\
\text { social media storytelling, and websites). }\end{array}$ \\
\hline & $\begin{array}{l}\text { Platforms and } \\
\text { channels }\end{array}$ & $\begin{array}{l}\text { List of platforms, channels, and specifica- } \\
\text { tion of the content for each of them. }\end{array}$ \\
\hline & $\begin{array}{l}\text { Service build } \\
\text { overview }\end{array}$ & $\begin{array}{l}\text { Scheme to identify what needs to be devel- } \\
\text { oped and what exists. }\end{array}$ \\
\hline & $\begin{array}{l}\text { Mechanic of } \\
\text { interaction }\end{array}$ & $\begin{array}{l}\text { Description of the mechanics of audience } \\
\text { interactions. }\end{array}$ \\
\hline & User journey & $\begin{array}{l}\text { Diagram that demonstrates the possible } \\
\text { paths through the project. It must give } \\
\text { ideas of the relationships that link different } \\
\text { contents. }\end{array}$ \\
\hline & Key events & $\begin{array}{l}\text { Narrative description of the contents listed } \\
\text { in the User Journey. } \\
\text { For each key event indicate: a) The call to } \\
\text { action, specifying if it is a rabbit hole or a } \\
\text { point-of-entry, b) What is the user's motiva- } \\
\text { tion, c) How it fits into the overall story. }\end{array}$ \\
\hline & Scheduling & $\begin{array}{l}\text { Timeline of the content distribution across } \\
\text { the channels: transmedia roll out. }\end{array}$ \\
\hline \multirow[t]{2}{*}{ BUSINESS MODEL } & Business model & $\begin{array}{l}\text { Description of the business model (e.g., } \\
\text { sponsorship, advertising, subscription, } \\
\text { direct sales, pay per use, product placement, } \\
\text { branding entertainment, or crowdfunding). }\end{array}$ \\
\hline & Team & $\begin{array}{l}\text { Identification of roles, responsibilities, and } \\
\text { skills. }\end{array}$ \\
\hline
\end{tabular}


TOPIC

PAPER FORMAT
SUBJECT

Idea, aim, target, target needs, story and plot, characters, location, tone of voice, moodboard, visual design, audience engagement, and production notes.

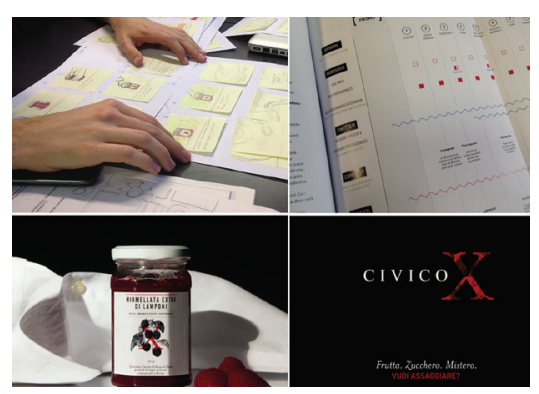

Figure 1

Storyboard, User journey, Tagline from 'Civico X' - Eleonora Campanella, Federica Caserio, Giovanni Manzini, Sophia Marostica, Alberto Mora, Samuele Schiatti-Laboratorio di sintesi finale "Fuoricampo", $2^{\circ}$ LM, School of Design, Politecnico di Milano. Lecturers: Marisa Galbiati,

Francesca Piredda, Katia Goldoni, Marco Ronchi; tutor: Mariana Ciancia, Simona Venditti, Gabriele Carbone, a.a. 2013-14.
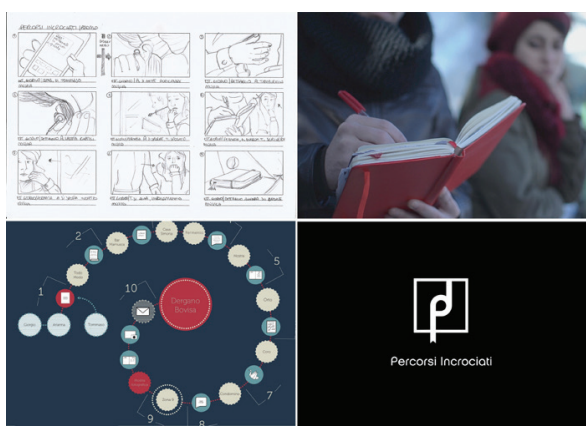

Figure 2

Storyboard, Frame, User journey from 'Percorsi Incrociati' - Giulia Barisone, Marialaura Gionfriddo, Valeria Guaragno, Valeria La Mantia, Federica Schirru, "Fuoricampo", $2^{\circ}$ LM, School of Design, Politecnico di Milano. Lecturers: Marisa Galbiati, Francesca Piredda, Katia Goldoni,

Marco Ronchi; tutor: Mariana Ciancia, Simona Venditti, Gabriele Carbone, a.a. 2013-14.

International Journal of Transmedia Literacy - 1.1 - December 2015 http://www.ledonline.it/transmedialiteracy/ 
Due to the short duration of the course (October 2013-January 2014), we asked students to develop only one of the expected channels: the storyline developed by the web series. This has become the subject of the second part of the hybrid document provided by them (paper format), in which the students have designed in detail not only the story and the engagement paths, but also the production notes.

The experience with the students has been an essential part of fully understanding the underlying processes in the development of multi-channel projects. The observation, monitoring, and revision of their work has been fundamental to the further development and exploration of insights and hypotheses that I had about the construction of the transmedia design framework. Thanks to the feedback obtained from this experience, I am refining this conceptual and operational tool not only for those who already had experience in designing transmedia experiences, but also for those who approach this field for the first time.

\section{CONCLUSION}

As explained above, due to the lack of common practices and a shared glossary, I applied a design perspective to my research, because "design thinking goes beside complexity thinking" (Pizzocaro 2000) and also "[d]esign research creates a place to braid theory and practice to make the work stronger". (Lunenfeld 2003, 10) What I inferred from my experience is that for researching into the transmedia field it is necessary to activate the dual role of researcher and designer (see Figure 3), with a continuous displacement of the observation point between the outer (objective) and the internal space (subjective). This is why I think it is useful to sustain the research with a design-oriented approach.

The researcher needs to activate an empathic relationship with the object of study, and in some cases, lose some objectivity in favor of direct involvement. When we design for an audience, we need to have an idea of people's feelings. In these cases, online communities and social networks are fundamental not only for information exchanges, but also "sites for experimentation with identities". (Lemke 2011, 590) This results in something like "learning by engaging". If the experience as an audience allows me to understand the dynamics of engagement and reception of content from an inside point-ofview, the teaching is helping me to understand the design processes of transmedia experiences through the transmission of tacit knowledge. 


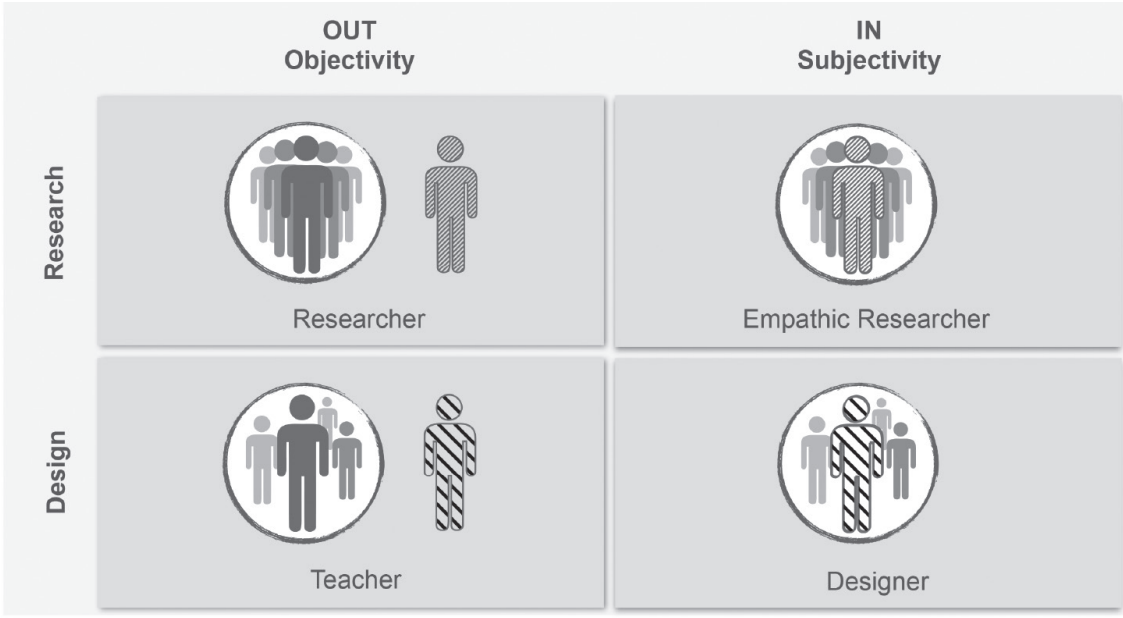

Figure 3 - The dual role of the researcher in the transmedia field.

\section{REFERENCES}

Brown, Tim. 2008. “Design Thinking.” Harvard Business Review, 86 (6): 84-92. http:// hbr.org/2008/06/design-thinking/ar/1.

Chow, Rosan and Wolfgang Jonas. 2008. "Beyond Dualisms in Methodology - an integrative design research medium ('MAPS') and some reflections." Undisciplined! Design Research Society Conference 2008. http://shura.shu.ac.uk/477/

Cross, Nigel. 2001. "Designerly Ways of Knowing: Design Discipline versus Design Science." Design Issues 17 (3): 49-55.

Dena, Christy. 2009. Transmedia Practice: Theorizing the Practice of Expressing a Fictional World Across Distinct Media and Environments - PhD thesis. Sydney: University of Sydney.

Ehn, Pelle. 2008. "Participation in design things." Proceedings of the Tenth Anniversary Conference on Participatory Design 2008. 92-101. http://dl.acm.org/citation.cfm? id=1795248.

Hayes, Gary P. 2011. "How to write a Transmedia Production Bible. A template for multi-platform producers.” Screen Australia. Last access February 09, 2014. URL: https://www.screenaustralia.gov.au/filmmaking/digital_resources.aspx.

Imagislab. 2013. "Plug Social TV.” Facebook. Last access February 10, 2014. URL: https://www.facebook.com/plugsocialtv. 
Imagislab. 2013. "Plug Social TV". Youtube. Last access February 10, 2014. URL: http://www.youtube.com/user/plugsocialtv.

Iron Sky. 2012. Directed by Timo Vuorensola. Blind Spot Pictures Oy, 27 Films Production and New Holland Pictures. Finland-Germany-Australia.

Iron Sky. 2013. "Iron Sky-The Coming Race. Crowdfunding the sequel of Iron Sky." Indiegogo. Last access February 13, 2014. URL: http://www.indiegogo.com/ projects/iron-sky-the-coming-race.

Jenkins, Henry. 2003. “Transmedia Storytelling.” Technology Review. Last access February 13, 2014. URL: http://www.technologyreview.com/biomedicine/13052/.

Jenkins, Henry. 2006. Convergence Culture: Where Old and New Media Collide. New York: New York University Press.

Jenkins, Henry, Sam Ford, and Joshua Green. 2013. Spreadable Media: Creating Value and Meaning in a Networked Culture. New York: New York University Press.

Kinder, Marsha. 1991. Playing with Power in Movies, Television, and Video Games: From Muppet Babies to Teenage Mutant Ninja Turtles. Berkeley and Los Angeles: University of California Press.

Kress, Gunther, and Theo Van Leeuwen. 2001. Multimodal discourse: the modes and media of contemporary communication. London: Hodder Education.

Laurel, Brenda. 1991. Computers as Theatre. Boston, MA: Addison-Wesley.

Laurel, Brenda, eds. 2003. Design Research. Methods and Perspectives. Cambridge: MIT Press.

Lee, Elan. 2010. “The evolution of storytelling." TED ${ }^{X}$ Seattle. Convening community through stories. Last access February 09, 2014. URL: http://tedxtalks.ted. com/video/TEDxSeattle-Elan-Lee-41610;search\%3Atag\%3A\%22TEDxSeat tle $\% 22$.

Lemke, Jay. 2011. “Transmedia Traversals: Marketing Meaning and Identity.” In Interdisciplinary Perspectives on Multimodality: Theory and Practice-Proceedings of the Third International Conference on Multimodality, edited by Anthony Baldry and Elena Montagna, 576-596. Campobasso: Palladino.

Lévy, Pierre. 1996. L'intelligenza collettiva. Per un'antropologia del cyberspazio. Milan: Feltrinelli.

Lunenfeld, Peter. 2003. "The Design Cluster." In Design Research. Methods and Perspectives, edited by Brenda Laurel, 10-15. Cambridge: MIT Press.

Manovich, Lev. 2001. The Language of New Media. Cambridge: The MIT Press.

Manzini, Ezio. 2000. "Design Research: Reasons and Possibilities. The Production of a Design Knowledge: taking time in the age of real-time". In Design plus Research, Proceedings of the Politecnico di Milano conference, edited by Silvia Pizzocaro, Amilton and Dijon De Moraes, 13-15. Milan: Politecnico di Milano.

Moggridge, Bill. 2010. Designing Media. Cambridge: The MIT Press.

Phillips, Andrea. 2012. A creator's guide to transmedia storytelling: bow to captivate and engage audiences across multiple platforms. New York: McGraw Hill. 
Piredda, Francesca. 2008. Design della comunicazione audiovisiva. Un approccio strategico per la "televisione debole". Milano: Franco Angeli.

Pizzocaro, Silvia. 2010. "The in-progress status of doctoral research in design. Reflections from two decades of local doctoral research". In Notes on Doctoral Research in Design. Contributions from the Politecnico di Milano, edited by Luca Guerrini, 91-102. Milan: Franco Angeli.

Pratten, Robert. 2011. Getting started in Transmedia Storytelling. A practical guide for beginners. Seattle: CreateSpace.

Pratten, Robert. 2011. "Transmedia Project Reference Guide (Bible)." Slideshare. Last access February 09, 2014. URL: http://www.slideshare.net/ZenFilms/ transmedia-project-reference-guide-bible.

Rampazzo Gambarato, Renira. 2013. "Transmedia Project Design: Theoretical and Analytical Considerations.” Baltic Screen Media Review 1 (2013): 81-100.

Red Right Hand Co. 2013. “The Black Chronicle.” Facebook. Last access February 13, 2014. URL: https://www.facebook.com/theblackchronicle.

Staffans, Simon. 2012. "One year in now media.” Slideshare. Last access February 09, 2014. URL: http://www.slideshare.net/Simon99/one-year-in-now-media.

Stewart, Sean and Jordan Weisman. 2006. Catby's Book: If Found Call 650-266-8233. Philadelphia: Running Press Kids.

The Cosmonaut. 2013. Directed by Nicolás Alcalá. Entropy Studio, Forma Pro Films and Pecera Estudio. Spain. 